\title{
Bacterial colonization as a potential source of nosocomial respiratory infections in two types of spirometer
}

\author{
F. Burgos*, A. Torres*, J. González**, J. Puig de la Bellacasa**, \\ R. Rodriguez-Roisin*, J. Roca*
}

Bacterial colonization as a potential source of nosocomial respiratory infections in two types of spirometer. F. Burgos, A. Torres, J. González, J. Puig de la Bellacasa, R. Rodriguez-Roisin, J. Roca. CERS Journals Ltd 1996.

ABSTRACT: The potential risk of spirometers in the transmission of respiratory infections has not been yet established. We performed a prospective cross-sectional study to determine the rate of colonization of a water-sealed spirometer and a pneumotachograph, and the potential risk of cross-transmission of microorganisms to patients using each of these devices.

Fifty four patients (aged 51 $\pm 18($ mean \pm SD) yrs) were included in the study. All of them had undergone forced spirometry with bronchodilator response by means of the water-sealed spirometer $(n=36)$ or the pneumotachograph $(n=18)$. None had a clinically apparent respiratory infection at the time of the study. Routine hygiene measures for respiratory equipment were performed before the study protocol. Samples for microbiological cultures of different parts both of the water-sealed spirometer (proximal and distal tubing, bell and water-bell) and pneumotachograph (proximal and distal tubing) were taken daily before and after the usual series of lung function tests during a 5 day period. Pharyngeal swab cultures were obtained before spirometry and 7 days later in each subject.

Thirty six out of a total of $40(90 \%)$ culture samples from the water-sealed spirometer showed microbial growth compared to 4 out of $30(13 \%)$ samples obtained from the pneumotachograph $(\mathrm{p}<0.0001)$. Significant colonization of the water-sealed spirometer was apparent after the third day of the study. The microorganisms most frequently isolated were Penicillium sp. (62\%), Pseudomonas fluorescens $(32 \%)$, and Burkholderia cepacea $(48 \%)$. Distal tubing, water and water-bell were the parts of the water-sealed spirometer that showed higher colonization counts $\left(\geq 10^{4}\right.$ colony-forming units $\left.(\mathrm{cfu}) \cdot \mathrm{mL}^{-1}\right)$. No transmission sequence of potentially pathogenic microorganisms from equipment to patients or vice versa could be demonstrated.

In summary, the water-sealed spirometer frequently became colonized by microorganisms. The potential hazard of such equipment as reservoirs of microorganisms suggests a need for the implementation of new hygiene measures for their maintenance.

Eur Respir J., 1996, 9, 2614-2619.
Serveis de *Pneumologia i Allérgia Respiratoria and $* *$ Microbiologia, Hospital Clínic, Departament de Medicina, Universitat de Barcelona, Spain.

Correspondence: A. Torres

Servei de Pneumologia

Hospital Clínic

Villarroel 170

08036 Barcelona

Spain

\section{Keywords:}

Colonization of respiratory equipment forced spirometry

lung function testing

prophylaxis of nosocomial infection

Received: January 41996

Accepted after revision August 161996

Supported by grants SEPAR/Roussel 1992, FIS (Fondo de Investigación Sanitaria) 93/0605, CIRIT (Comissió Interdepartamental per a la Recerca i Tecnologia), and, ECSC 6975/92 (European Coal and Steel Community).
The contamination of respiratory therapy equipment can lead to the aerosol inoculation of pathogenic microorganisms to the oropharynx, or even directly to the lower airways, in patients undergoing these procedures [1-3]. Spirometers are the most commonly used systems in the pulmonary function laboratory. This type of equipment is transferred from patient to patient several times daily. Thus, these systems should be considered as potential sources of bacterial colonization and subsequent transmission [4]. However, the actual hazard of such equipment in the development of respiratory infections is not well-known. Accordingly, standardized preventive measures have not been validated [5]. HazALEus et al. [6] reported transmission of Mycobacterium tuberculosis from one patient to 22 others in whom a dry-seal spirometer was used. A simulated model of spirometer colonization suggested that mouthpieces and spirometer tubing may become contaminated with micro-organisms and should not be shared among patients [4]. Some authors have suggested that colonization of spirometers could be prevented by using anti-bacterial filters [7].

We performed a sequential study to determine the role of two different commonly used devices: 1) water-sealed spirometers; and 2) pneumotachographs, as reservoirs for bacterial colonization and subsequent transmission. Specifically, we cultured several parts of the equipment throughout a 5 day period. Additionally, the patients who used these instruments were followed-up during a 1 week period. 


\section{Material and methods}

\section{Equipment}

We investigated two types of spirometer: a watersealed spirometer (Biomedin ${ }^{\circledR}$; Padova, Italy) and a modified pneumotachograph heated flow transducer (MGC® 1070; Medical Graphics Co., St. Paul, MN, USA), routinely used in our laboratory for the measurement of forced spirometry and the bronchodilator response. The weekly hygiene maintenance for these devices is as follows: tubing and connections both the water-sealed spirometer and the pneumotachograph were sterilized. The water from the reservoir in the water-sealed spirometer was removed and replaced with sterile distilled water from commercial flasks, and the bell was scrubbed with water and soap. The resistance of the pneumotachograph was cleansed with water and soap. Subsequently, it was dried with compressed air. These procedures were performed in full before the study protocol.

\section{Study protocol}

Overall, a mean of 2,500 spirometric evaluations are performed annually in our institution. Twelve routine spirometric evaluations are performed daily on a 1:2 ratio (pneumotachograph:water-sealed). Accordingly, the study was randomized for the pneumotachograph and for the water-sealed spirometer at a ratio of 1:2. This was performed sequentially over a period of 5 days. The study period was randomly chosen, and lasted from Monday until Friday. Patients performed forced spirometric manoeuvres with bronchodilator response according to the American Thoracic Society (ATS) standards [8]. A sterile mouthpiece for tubing connection was used for each patient. Patients with active respiratory infection were excluded from the study, since we wanted to reproduce the routine standard policy of our laboratory. Patients were also evaluated for the development of clinical symptoms of respiratory infection, such as fever, cough, purulent secretions and abnormal pulmonary auscultation, immediately after spirometry had been performed and again 1 week later. In each patient, pharyngeal swab samples were collected according to a standard method before spirometry and 1 week later.

Samples of different parts of the equipment were taken daily just before and after performing a series of spirometric evaluations. Regarding the pneumotachograph, samples of the proximal and distal parts of the tubing connection to mouthpiece, and the resistance were taken for quantitative bacterial cultures (fig. 1). With respect to the water-sealed spirometer, samples were taken both from the proximal and distal parts of the breathing tubing, the water of the reservoir located between the bell and the cylinder, and finally from the internal surface of the bell (fig. 2). All samples, except water, were collected using a moist, sterile, cotton-tipped applicator (Modified Transport Medium, Eurotubo®; Barcelona, Spain). All samples, except water, were resuspended in $1 \mathrm{~mL}$ of saline. An undiluted sample from the water reservoir $(1 \mathrm{~mL})$ was collected using a sterile plastic syringe. All samples were immediately transported to the microbiology laboratory. The process

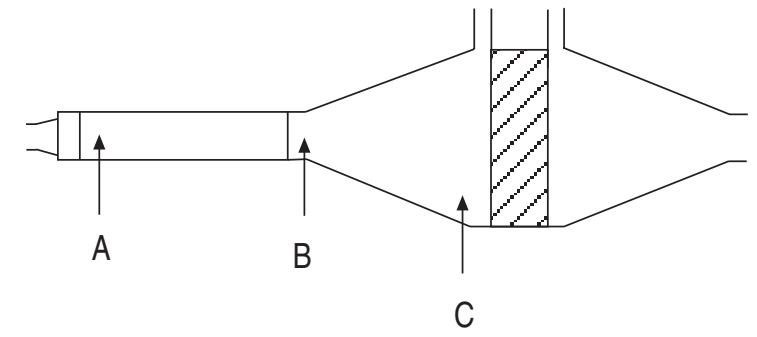

Fig. 1. - Schematic representation of the different parts of the Lilly pneumotachograph. A: proximal; B: distal; C: resistance.

of sampling was always performed by the same person (FB) in a standardized way.

\section{Microbiological processing}

All samples obtained were serially diluted (1:10, 1:100 and 1:1000) using sterile saline. One hundred microlitres of each dilution were plated into the following agar media: 5\% sheep blood, chocolate, McConkey, BCYE$\alpha$, and Sabouraud-dextrose. All cultures were incubated at $37^{\circ} \mathrm{C}$ under aerobic conditions and in $\mathrm{CO}_{2}$-enriched atmosphere, except Sabouraud-dextrose incubated at $30^{\circ} \mathrm{C}$. Cultures were evaluated for growth daily and were discarded, if negative, after 5 days, with the exception of Sabouraud-dextrose which was evaluated weekly and discarded at 4 weeks. Results were expressed as colonyforming units $(\mathrm{cfu}) \cdot \mathrm{mL}^{-1}$. This represents the concentration of the initial solution. The lower detection limit for bacteria was $10^{2} \mathrm{cfu} \cdot \mathrm{mL}^{-1}$. The microorganisms isolated were identified according to standardized methods [9].

\section{Statistical analysis}

Results are expressed as mean \pm sD. Mann-Whitney's test was used to compare means. A p-values of less than 0.05 was considered to be statistically significant [10].

\section{Results}

\section{Patients' characteristics}

Fifty four patients (mean \pm sD age $51 \pm 18$ yrs) programmed for forced spirometry and bronchodilator response

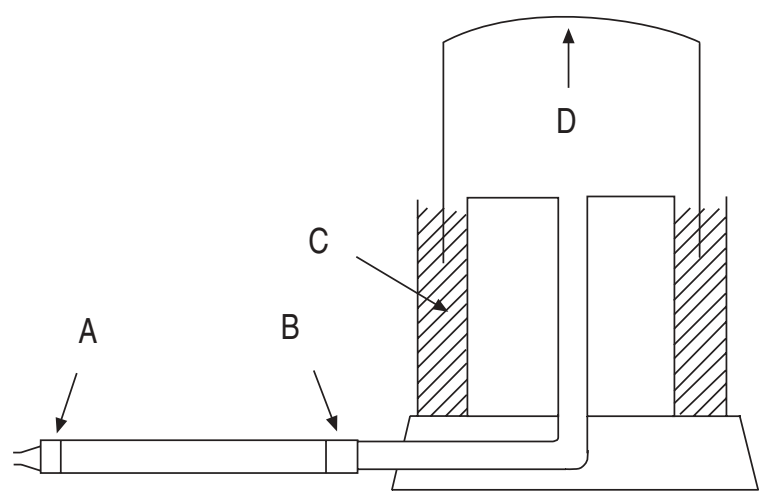

Fig. 2. - Schematic representation of the different parts of the watersealed spirometer. A: proximal; B: Distal; C; water; D: water-bell. 
Table 1. - Microorganisms isolated from the watersealed spirometer $(n=40)$

\begin{tabular}{llr}
\hline \multicolumn{1}{c}{ Group } & Microorganism & $\mathrm{n}$ \\
\hline Gram-negative cocci & Neisseria sp. & 1 \\
Gram-positive cocci & Staphyloccus epidermis & 3 \\
& Streptococcus viridans & 1 \\
Gram-negative bacilli & Burkholderia cepacea & 19 \\
& Pseudomonas fluorescens & 13 \\
& Pseudomonas aeruginosa & 5 \\
& Xanthomonas maltophilia & 5 \\
& Enterobacter cloacae & 5 \\
& Pseudomonas vesicularis & 1 \\
Fungi & Penicillium sp. & 25 \\
& Candida sp. & 1 \\
\hline
\end{tabular}

Table 2. - Number of microorganisms isolated in different parts of the water-sealed spirometer in relation to quantitative cultures

\begin{tabular}{lcccccc}
\hline & \multicolumn{6}{c}{ Microorganisms } \\
& Neg & $10^{3}$ & $10^{3}-10^{4}$ & $10^{4}-10^{5}$ & $10^{5}-10^{6}$ & $10^{6}$ \\
\hline Proximal tubing & 2 & 5 & - & 1 & 2 & - \\
Distal tubing & - & 2 & 2 & 2 & 3 & 1 \\
Water & 1 & 2 & 3 & - & 4 & - \\
Water-bell & 1 & 1 & 2 & 3 & 2 & 1 \\
\hline
\end{tabular}

The data represent the number of isolations. cfu: colony-forming units; Neg: negative.

in our laboratory during a 1 week period in springtime were included in the study. Thirty one patients were male and 23 female. According to the routine policy of our laboratory, forced spirometry was performed with the water-sealed spirometer in 36 patients $(67 \%)$. In the remaining $18(33 \%)$ patients, it was performed using a pneumotachograph. The clinical indications for forced spirometry were control of the evolution of respiratory illness in 48 patients ((asthma (21), chronic obstructive pulmonary disease (COPD) (17) and pulmonary fibrosis (10)), and preoperative evaluation in 6 patients. None of the patients had a clinically apparent pulmonary infection.

\section{Water-sealed spirometer}

At least one microorganism was isolated in 36 out of $40(90 \%)$ samples, as shown in table 1 . The most frequently isolated microorganisms were Penicillium sp. (62\%), Pseudomonas fluorescens (32\%) and Burkholderia cepacea $(48 \%)$. In all but four instances, microorganisms were always concomitantly isolated from at least two samples from different parts of the spirometer. Table 2 shows microbial concentrations cultured in different parts of the water-sealed spirometer. Nineteen samples (48\%) showed microorganisms yielding counts $\geq 10^{4} \mathrm{cfu} \cdot \mathrm{mL}^{-1}, 17(42 \%) \leq 10^{4} \mathrm{cfu} \cdot \mathrm{mL}^{-1}$, and four were negative (two samples from the proximal tubing, one from the water, and one from the bell). Proximal tubing cultures showed the lowest degree of colonization compared to the remaining samples ( 5 out of 10 samples had counts $\leq 10^{3} \mathrm{cfu} \cdot \mathrm{mL}^{-1}$ and two were negative) (table 2).

The sequential pattern of colonization in samples isolated from different parts of the water-sealed spirometer during the 5 day study period is illustrated in figure 3. Peaks of colonization caused by Gram-negative and Gram-positive cocci (Neisseria sp. and Staphylococcus epidermidis) were observed in distal tubing (on Day 3) and water bell cultures (on Day 5) (fig. 3a). A peak of colonization by fungi (Penicilium sp.) was detected on Day 3 of the study in distal tubing cultures (fig. 3b). Figure $3 \mathrm{c}$ shows a colonization peak caused by Gramnegative bacilli in proximal tubing cultures at Day 4 (P. fluorescens and B. cepacea). The level of colonization decreased at Day 5 in the same samples (fig. $3 \mathrm{c})$. Colonization by gram-negative bacilli in the remaining parts of the water-sealed spirometer (proximal, water, water bell) was also observed on the last 2 days of the study. Specifically, at Day 5 the microorganisms isolated were the following: 1) proximal tubing: $P$. fluorescens, P. cepacea and Pseudomonas aeruginosa; 2) bell: $P$. fluorescens, B. cepacea, $P$. aeruginosa and Enterobacter cloacae: 3) water-bell: P. fluorescens, B. cepacea, P. aeruginosa; and E. cloacae.
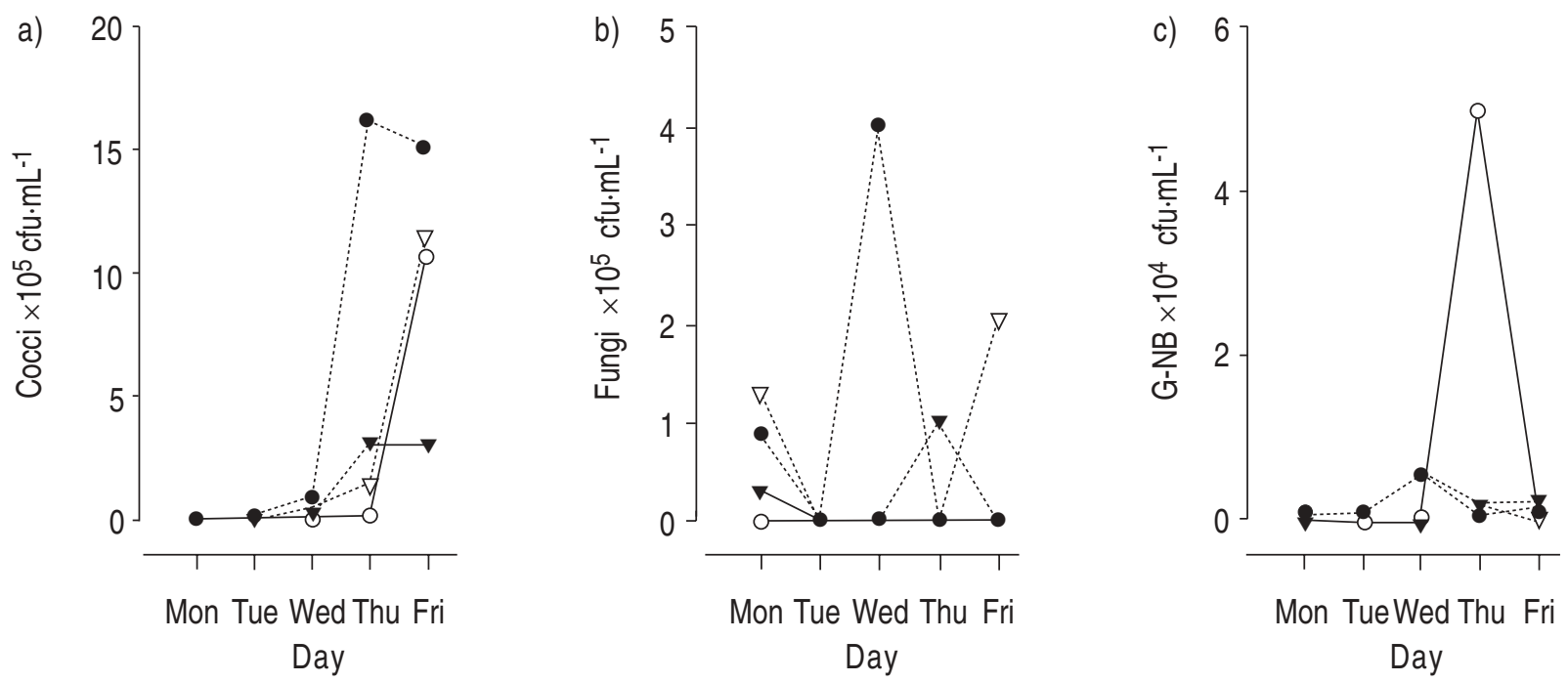

Fig. 3. - Mean concentration of: a) Gram-negative and Gram-positive cocci; b) fungi; and c) Gram-negative bacilli (G-NB) isolated from the different parts of the water-sealed spirometer during the 5 day study period. $-\mathrm{O}-$ : proximal tubing; $-\bullet-$ : distal tubing; — $-\nabla$ : water-bell; - - - : water. 
Table 3. - Presence of microorganisms in pharyngeal swabs of patients

\begin{tabular}{|c|c|c|c|c|c|}
\hline \multirow{2}{*}{ Micoorganism } & \multirow{2}{*}{$\begin{array}{c}\text { Before } \\
\text { spirometry } \\
\mathrm{n}^{+}\end{array}$} & \multirow{2}{*}{$\begin{array}{c}1 \text { week } \\
\text { later } \\
n^{+}\end{array}$} & \multicolumn{3}{|c|}{ Colony count ( 1 week later $)$} \\
\hline & & & $\underset{\mathrm{n}^{\dagger}}{\text { Increase }}$ & $\underset{\mathrm{n}^{\dagger}}{\text { Decrease }}$ & No change \\
\hline Neisseria sp. & 35 & 36 & 15 & 17 & 4 \\
\hline Staphylococcus epidermidis & 35 & 36 & 12 & 11 & 13 \\
\hline Streptococcus viridans & 35 & 36 & 16 & 16 & 4 \\
\hline Corynebacterium sp. & 3 & 8 & 6 & 4 & 1 \\
\hline
\end{tabular}

+: Number of cases in which each microorganism was isolated; $\uparrow$ : number of cases in which the colony count increased, decreased or was unchanged, respectively.

\section{Pneumotachograph}

Colonization was observed in only 4 out of $30(13 \%)$ cultured samples obtained from the pneumotachograph compared to 36 out of $40(90 \%)$ from the water-sealed spirometer $(\mathrm{p}<0.0001)$. Furthermore, the colonization never exceeded $10^{3} \mathrm{cfu} \cdot \mathrm{mL}^{-1}$. The microorganisms isolated were $S$. epidermidis and Penicillium sp. at Days 1, 3 and 4 of the study.

\section{Pharyngeal swabs}

A total of 108 pharyngeal swab samples were obtained. Seventy two were from patients who used the water-sealed spirometer and the remaining 36 were from patients using the pneumotachograph. Table 3 shows the different microorganisms isolated in the initial and final samples of pharyngeal swabs. There were no qualitative changes in pharyngeal colonization when comparing final (1 week after the spirometry) to initial samples (before spirometry). Exceptionally, nonpotentially pathogenic microorganisms, such as Neisseria sp. S. epidermidis and S.viridans, were isolated from the distal tubing, water-bell and waterbell, respectively, and concomitantly from pharyngeal swabs. None of the patients showed changes or new respiratory signs and/or symptoms suggestive of respiratory infection during 1 week after spirometry.

\section{Discussion}

The main finding from the present study is that bacterial colonization was virtually absent in the Lilly pneumotachograph but occurred frequently and in different parts of the water-sealed spirometer. Although we could not prove changes in the pharyngeal flora after spirometry, the colonization of this equipment should be considered as a potential risk factor for transmission of respiratory infections.

In the aetiopathogenic sequence of nosocomial respiratory infections, inhaling contaminated aerosols from respiratory therapy equipment is one of the accepted mechanisms [11-13]. The later is not infrequent in critically-ill intubated patients. Contaminated aerosols have been demonstrated to originate from contaminated nebulizers [2], water condensate in ventilator tubing [1], and even peak flow meters [14] and resuscitator bags [15].

Information regarding the potential risk of transmission due to colonization of equipment for measuring respiratory function in pulmonary laboratories is scanty or anecdotal $[4,6,16]$. For instance, HazAleus and BerdischewsKy [6] reported a small outbreak caused by $M$. tuberculosis contaminating apparatus for pulmonary function testing. Rutala et al. [4] found colonization of mouthpieces of dry spirometers from patients with active pulmonary infections, although the remaining parts of the equipment remained uncolonized, suggesting that it is unnecessary to routinely disinfect interior surfaces of spirometers after use by infected patients. Houston et al. [16] investigated the bacterial pathogens isolated from the unsterilized tube and spirometer bellows of a Vitalograph ${ }^{\circledR}$ used by 1,000 patients over a 4 week period. The most common organisms isolated were: Acinetobacter sp., Flavobacterium sp., S. epidermidis, Streptococcus sp., and fungi.

We found no colonization in the pneumotachograph. This could be explained by the high temperatures [17] obtained around the proximal tubing, inhibiting bacterial and fungal growth. However, the water-sealed spirometer became colonized in various parts. This colonization was important in quantitative terms, indicating a high level of contamination. However, there are some considerations in the present study that deserve particular attention regarding the latter finding. Firstly, patients with active pulmonary infections were not studied, since we wanted to reproduce the standard policy of our laboratory. It is possible that the risk of transmission from spirometers to patients may be higher when studying patients with active respiratory infections. However, RUTALA et al. [4], studying bacterial colonization of dry-rolling seal spirometers in active pulmonary infections, did not find contamination inside the spirometers.

Secondly, the study was performed sequentially during a 5 day period, and colonization of the equipment occurred after the third day in spite of the use of routine hygiene measures. Thirdly, some isolated microorganisms (e.g. P. aeruginosa or E. cloacae) are frequent pulmonary pathogens. Nevertheless and although we cannot discard transient pharyngeal colonization, we could not isolate these microorganisms from the oropharynx of the patients. However, a possible limitation of our study regarding transmission from spirometers to patients is that we did not examine sputum cultures, due to the difficulty of obtaining these respiratory samples.

Finally, although some contaminants of the spirometer (e.g. Neisseria sp., S. epidermidis, Streptococcus viridans, Candida albicans and E. cloacae) could have been transmitted from patients, most of the microorganisms isolated were environmental, such as Penicillium sp. and P. fluorescens. The high frequency of Penicillium sp. is an uncommon fact. Most surprisingly this fungus was isolated at an early stage in a disinfected instrument (fig. 3b), again suggesting easy environmental contamination. 
In this study, it is impossible to ascertain whether there was transient pharyngeal and/or airway colonization from equipment to patients, since pharyngeal swabs were not collected sequentially, but if colonization occurred it was not of clinical relevance. With the exception of anecdotal reports [6], there is no evidence of transmission from contaminated spirometers to noncritically ill patients and the results of the present study support this statement. However, water-sealed spirometers may be potential risk factors for transmission in immunosuppressed patients with altered humoral and cellular defences. Taking the examples of this study, the recovery of bacteria on the surface of spirometer tubing or from water does not necessarily imply that these bacteria will be aerosolized during subsequent inspiratory manoeuvres. Future, experimental studies should answer this question.

Prophylactic measures against colonization of spirometers should consider enhancement of the routine hygiene measures and strict control of patients who undergo the test. Unfortunately, these measures have never been clearly standardized and the optimal frequency for disinfection or sterilization of tubing, valves and manifolds has not been established. Some recommendations have been suggested in a recent ATS statement, that include, at least, decontamination of breathing tubes between patients when using a closed-circuit technique [8].

Another prophylactic measure could be the inclusion of in-line antibacterial filters. Some authors have suggested that the use of antibacterial filters may prevent bacterial contamination of spirometers and also have antiviral barrier properties [18]. For instance, WA 3 ER et al. [7] demonstrated that by using filters the bacterial burden of the spirometers decreased dramatically from 45,200 to $50 \mathrm{cfu} \cdot \mathrm{mL}$. Another study demonstrated a high efficiency of these filters in removing exhaled bacteria after spirometry [18]. However, controversy exists regarding the potential alteration of pulmonary function test measurements when using these filters [19]. Significant differences between pulmonary function test measurements with and without the use of filters were found by Fuso et al. [20]. However, the authors did not consider this to be clinically significant, since changes due to the filter were within the intraindividual variability of repeated measurements.

The present study was not designed to evaluate viral contamination or other types of microorganism difficult to culture on standard media, such as M. tuberculosis. In fact, patients with suspicion of pulmonary tuberculosis were excluded from this study, since individual chest radiographs were always examined according to the routine of our laboratory. It seems logical to anticipate that spirometers (particularly during inspiratory manoeuvres) may serve as viral or mycobacterial transmitters, since aerosolized droplets containing contaminated particles are the primary means of transmission of viral or mycobacterial pulmonary infections [21]. A strict control of patients, avoiding the study of those subjects with clinical suspicion of active respiratory infection, could be an effective preventive approach for viral and mycobacterial respiratory infections.

Respiratory technicians are cautious regarding the performance of spirometric evaluation on patients infected with human immunodeficiency virus (HIV). Although the virus has been found in saliva, there is no proven case of transmission by this type of body fluid. Nevertheless, theoretically, this possibility cannot be ruled out. Reserving particular equipment for use by infected people is difficult. Moreover, carriers of HIV are underdiagnosed or may not wish to be recognized. Since screening for HIV presents legal and ethical problems, DenISON et al. [22] advocate the universal application of safeguards against cross-infection, including the use of disposable components.

Legionella pneumophila colonizes portable water, and respiratory equipment filled or rinsed with tap water may serve as a secondary reservoir for these infections [23]. Contaminated aerosols generated by respiratory equipment could then transmit airborne L. pneumophila to the respiratory tract of patients. Hypothetically, this could be the case with water-sealed spirometers. $L$. pneumophila did not grow in any of the samples taken in our study, although our bacteriological technique (serial dilution) is not the most adequate for culturing $\mathrm{L}$ pneumophilia and we could not rule out that this microorganism may be more relevant. We consider it to be advisable to perform a periodic surveillance for Legionella spp. in the equipment, particularly watersealed spirometers, and also recommend the systematic use of distilled water.

In summary, colonization of the pneumotachograph is uncommon. On the other hand, water-sealed spirometers can easily be contaminated with environmental flora and potentially pathogenic microorganisms. Although we could not demonstrate transmission of respiratory infection from this equipment, water-sealed spirometers have a potential risk in the development of these infections. The implementation of new and daily hygiene measures for the maintenance of such equipment is desirable.

Acknowledgements: The authors are grateful to C. Martinez, M. El-Ebiary and the technical staff of our Service for their co-operation in this study.

\section{References}

1. Craven DE, Goularte TA, Make BJ. Contaminated condensate in mechanical ventilation circuits. Am Rev Respir Dis 1984; 129: 625-628.

2. Pierce AK, Sanford JP. Bacterial contamination of aerosols. Arch Intern Med 1973; 131: 156-159.

3. Craven DE, Barber TW, Steeger KA, Montecalvo MA. Nosocomial pneumonia in the 1990s: update of epidemiology and risk factors. Semin Respir Infect 1990; 5: 157-172.

4. Rutala DR, Rutala WA, Weber DJ, Thomann CA. Infection risk associated with spirometry. Infect Control Hosp Epidemiol 1991; 12: 89-92.

5. Mahler DA, Locke J, Pulmonary function testing. Clin Chest Med 1989; 10: 129-134.

6. Hazaleus RE, Cole J, Berdischewsky M. Tuberculin skin test conversion from exposure to contaminated pulmonary function testing apparatus. Respir Care 1981; 26: 53-55.

7. Waßer F, Stau $\beta$ R, Müller RL, et al. Air filters prevent the microbial contamination of spirometers and should be used to protect immune-compromised patients. Eur Respir J 1992; 5: 140s-141s. 
8. American Thoracic Society. Standardization of spirometry: 1994 update. Am J Respir Crit Care Med 1995; 152: 1107-1136.

9. Balows A, Hausler Jr WJ, Herrmann KL, Isenberg HD, Shadomy HS, (eds). Manual of Clinical Microbiology. Washington, DC, American Society for Microbiology, 1991; 5th edn, Section III.

10. Norusis MJ. SPSS PC+ statistics v 4.0. Statistical Package for Social Sciences. SPSS/Inc., 1990.

11. Cross AS, Roup B. Role of respiratory devices in endemic nosocomial pneumonia. Am J Med 1981; 70: 681-685.

12. Tablan OC, Anderson LJ, Arden NH, et al. and the Hospital Infection Control Practices Advisory Committee. Guideline for prevention of nosocomial pneumonia Part I. Issues on prevention of nosocomial pneumonia. Respir Care 1994; 39: 1191-1236.

13. Barbat J, Torres A, Arnaiz J. Los equipos de terapéutica respiratoria como factor de riesgo en las neumonías nosocomiales. Med Clin (Barc)1986; 87: 119-124.

14. Ayres JG, Whitehead J, Boldy DA, Dyas A. Fungal contamination of mini peak flow meters. Respir Med 1989; 89: 503-504.

15. Hartstein AI, Rashad AL, Liebler JM, et al. Multiple intensive care unit outbreak of Acinetobacter calcoaceticus subspecies anitratus respiratory infection and colonization associated with contaminated, reusable ventilator circuits and resuscitation bags. Am J Med 1988; 85: 624-631.

16. Houston K, Parry P, Smith AP. Have you looked into your spirometer recently? Breath 1981; 12: 10-11.

17. Comhaire A, Lamy M. Contamination rate of sterilized ventilators in an ICU. Crit Care Med 1981; 9: 546-548.

18. Kirk YL, Kendall K, Ashworth HA, Hunter PR. Laboratory evaluation of a filter for the control of cross-infection during pulmonary function testing. J Hosp Infect 1992; 20: 193-198.

19. Guimond VJ, Gibson NN. Effects of in-line filters on spirometry. Can J Resp Therapy 1991; 26: 9-11.

20. Fuso L, Accardo D, Bevignani G, Ferrante E, DellaCorte A, Pistelli R. Effects of a filter at the mouth on pulmonary function tests. Eur Respir J 1995; 8: 314-317.

21. Ruben FL, Nguyen MT. Viral pneumonitis. Clin Chest Med 1991; 12: 223-235.

22. Denison DM, Cramer DS, Hanson PJ. Lung function testing and AIDS. Respir Med 1989; 83: 133-138.

23. Woo AH, Goetz A, Yu VL. Transmission of Legionella by respiratory equipment and aerosol generating devices. Chest 1992; 102(5): 1586-1590. 